\title{
DIFFUSIVE AND DISPLACIVE PHASE TRANSFORMATIONS UNDER HIGH PRESSURE TORSION
}

Boris Straumal $^{1,2,23)^{*}}$, Askar Kilmametov ${ }^{(1,3)}$, Andrey Mazilkin ${ }^{(1), 3)}$, Olga Kogtenkova ${ }^{(1)}$, Brigitte Baretzky ${ }^{3)}$, Anna Korneva ${ }^{4)}$, Pawel Zięba ${ }^{4)}$

${ }^{1}$ Institute of Solid State Physics and Cheronogolovka Scientific Center of RAS, Chernogolovka, Russia

${ }^{2}$ National University of Science and Technology «MISIS», Moscow, Russia

${ }^{3}$ Karlsruhe Institute of Technology, Institute of Nanotechnology, Eggenstein-Leopoldshafen, Germany

${ }^{4}$ Institute of Metallurgy and Materials Science, Polish Academy of Sciences, 25 Reymonta Street, 30-059 Cracow, Poland

Received: 12.08 .2019

Accepted: 02.12.2019

${ }^{*}$ Corresponding author: straumal@issp.ac.ru, Tel.: +7 9166768673, Institute of Solid State

Physics RAS, Ac, Ossipyan str. 2, 142432 Chernogolovka, Russia

\begin{abstract}
Severe plastic deformation (SPD) can induce various phase transformations. After a certain strain, the dynamic equilibrium establishes between defects production by an external force and their relaxation (annihilation). The grain size, hardness, phase composition etc. in this steady-state does not depend on the initial state of a material and is, therefore, equifinal. In this review we discuss the competition between precipitation and dissolution of precipitates, amorphization and (nano)crystallization, SPD-induced accelerated mass-transfer, allotropic and martensitic transitions and formation of grain boundary phases.
\end{abstract}

Keywords: severe plastic deformation, phase transformations, thermodynamics, kinetics

\section{Introduction}

Severe plastic deformation (SPD) is a novel class of mechanical treatment which permits to apply a very high strain to the material without its failure, which is not possible with traditional methods. SPD always leads to strong grain refinement or even to amorphization of a material. At the same time, SPD can drive the phase transformations [1-6]. In other words the phases in a material before and after SPD can be different. Frequently, after SPD a material contains such phases as if it was annealed at elevated temperature and then quickly quenched [3]. Thus, SPD opens completely new ways for tailoring microstructure and properties of materials. The understanding of SPDdriven phase transformations is the topic of this review.

\section{Steady-state during SPD}

The important feature of SPD is that the sample cannot break during straining, and its shape remains more or less unchanged. It is especially well pronounced in case of high pressure torsion (HPT). The small disk between two anvils conserves its shape independently on number of anvils rotations. The torsion can continue until the anvils (typically made of WC-Co alloy) break. For example, in case of HPT of Nd-Fe-B alloys the anvils withstand only about 20 rotations [7, 8] but 
in case of soft aluminium-, magnesium- or copper-based alloys HPT can continue up to hundreds or even thousands anvil rotations [9-13]. When the straining starts, the amount of lattice defects (like vacancies, dislocations, grain boundaries) expectedly increases. However, it would be strange to anticipate that the number of defects would increase infinitely during endless anvil rotations. Even if the HPT proceeds at room temperature when the coefficients of bulk diffusion are below $10^{-30}-10^{-40} \mathrm{~m}^{2} / \mathrm{s}$, the relaxation starts. Its rate increases with increasing concentration of defects until the dynamic equilibrium establishes. In other words, the rate of defects production becomes equal to the rate of their annihilation (relaxation). Here it is appropriate to mention that usually HPT (and generally SPD) takes place at room temperature and the samples are almost not heated during HPT $[14,15]$. After HPT treatment they are usually just a little bit warm. The direct temperature measurements between anvils witness that the temperature during SPD does not exceed about $40^{\circ} \mathrm{C}[16,17]$.

Thus, after a certain number of anvil rotations, the rate of defects production becomes equal to the rate of their annihilation (relaxation) and the steady-state is reached [5, 18]. The easiest way to observe it is to measure the torsion torque during HPT. It increases during the transient stage, but quickly saturates after 1-1.5 rotations in case of Al-, $\mathrm{Cu}-, \mathrm{Mg}$ - or even Ti-based alloys $[1,5,13$, $16,19]$. In case of harder alloys like Nd-Fe-B the torsion torques saturates after 2-2.5 anvil rotations $[5,7,8]$. Not only torsion torque, but also the values of the properties or structural parameters saturate in the steady state. For example, the most prominent feature of SPD is the grain refinement $[13,20-25]$. If one starts to deform the material with grain size of several millimetres, it quickly decreases down to few hundreds of nanometers. Then, the grain size reaches the steady-state value, stabilises and does not decrease anymore [17, 26-29]. In the same material, the steady-state grain size depends first of all on the SPD mode. For example, the smallest grain size in copper and copper-based alloys of about $15 \mathrm{~nm}$ is reached by the ball milling (Fig. 1) [30]. The second strongest grain refiner is HPT [1,31-36]. This is followed by planar twist channel angular extrusion (PTCAE) [37], equal channel angular pressing (ECAP) [34, 38], equal channel angular pressing with the subsequent HPT (ECAP+HPT) [34], equal channel angular pressing with following cold rolling (ECAP + CR) [39], simple shear extrusion (SSE) [40, 41], and constrained groove pressing (CGP) [42]. Same tendency is true also for aluminium and its alloys [43]. The steady-state grain size is also the function of HPT pressure, strain rate and temperature $[5,18]$. It decreases with increasing melting temperature, atomic bond energy, specific heat capacity and activation energy for self-diffusion $[18,44]$. One has to underline that the grain size in the dynamic equilibrium is a real steady-state value. It means that it is reached not only "from the top" but also "from the bottom". In other words, if one starts HPT of steel from the coarsegrained sample, one quickly reaches the grain size of 15-20 nm [28, 45-51] (Fig. 2). However, if one starts to deform the nanocrystalline steel sample with grain size of $10 \mathrm{~nm}$ produced by mechanical alloying, the grains do not become smaller. To the contrary, they grow during SPD up to the same steady-state value of 15-20 nm (Fig. 2) [9]. Similar phenomenon was observed also in nickel [52, 53] and copper [54].

Together with observation of grain refinement, a huge amount of experimental data is collected on the Vickers microhardness during and after SPD of copper, aluminium, titanium, magnesium alloys, steels etc. [10, 17, 29, 55-67]. Usually microhardness increases during SPD [10, 17, 29, 55-67]. It correlates also with tensile strength [13, 24, 25, 57, 60, 68-70]. It is true not only for rotation angle for HPT but also for number of passes during equal channel angular pressing (ECAP) [62]. The main mechanism here is the Hall-Petch hardening due to the grain refinement 
[71]. Few exclusions only support this fact. For example, in Al-Zn alloys the Hall-Petch hardening competes with softening driven by the decomposition of (Al) solid solution, and after HPT the alloy is softer than before HPT (Fig. 3) [31, 56, 72, 73]. Similar to the grain size, the hardness value is also a function of material and SPD mode. So, by the increase of the purity of aluminium, one observes the transition from hardening to softening during HPT [74]. Thus, when the initial hardness of an alloy is higher than the steady-state one, then softening rather than hardening is observed during SPD [72].

The decrease of grain size and increase of Vickers microhardness after HPT, ECAP and alternating roll bonding (ARB) correlates with increase of electrical resistivity of copper [62]. It is important to underline that different properties (grain size, hardness, torsion torque, lattice parameter, resistivity etc.) reach steady state not at the same time.

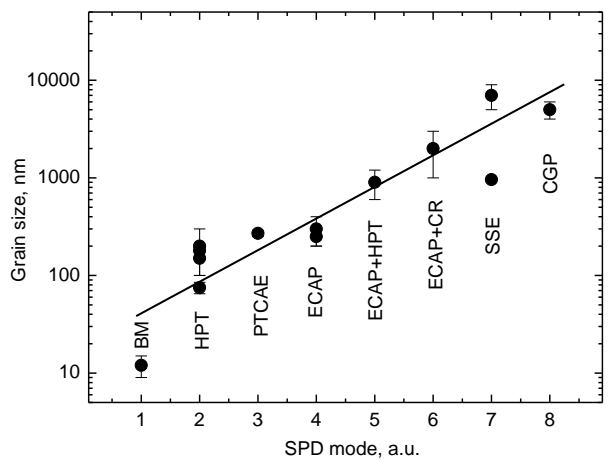

Fig. 1 Steady-state grain size in copper subjected to the different SPD modes: 1 - Ball milling (BM) [30], 2 - High pressure torsion (HPT) [1, 31-36], 3 - Planar twist channel angular extrusion (PTCAE) [37], 4 - Equal channel angular pressing (ECAP) [34, 38], 5 - ECAP+HPT [34], 6 - Equal channel angular pressing with following cold rolling (ECAP + CR) [39], 7 - Simple shear extrusion (SSE) [40, 41], 8 - Constrained groove pressing (CGP) [42]



Fig. 2 Grain size plotted vs. number of torsions for pure coarse-grained steel sample (filled circles) [46] and nanocrystalline steel produced by mechanical alloying (open squares) [9]

\section{Competition between dissolution of precipitates and decomposition of supersaturated solid solution}

It has been long time generally believed that SPD always leads to the grain refinement $[23,75]$ and to the dissolution of precipitates and formation of supersaturated solid solution. However, we demonstrated above that the grain size decreased during SPD only in the case if the grains in the initial sample before SPD are larger than those in the steady-state. If the grains before SPD are smaller than in the steady state, they will grow during the deformation and reach the same steadystate grain size "from below" (see Fig. 2). This is true also for the SPD-induced 
hardening/softening (see Fig. 3). Similar is the situation with dissolution/precipitation process. In the steady-state during SPD a certain concentration in the solid solution $c_{\mathrm{ss}}$ establishes. Its value is controlled by the dynamic equilibrium between competing dissolution and precipitation. If the initial concentration in a solid solution $c_{\text {init }}$ is below $c_{\mathrm{ss}}$, it increases during SPD and precipitates dissolve. Otherwise, if $c_{\text {init }}>c_{\mathrm{ss}}$, the concentration of second component in a solid solution decreases and new precipitates appear (so-called dynamic ageing). For the first time such dynamic ageing has been observed in $\mathrm{Al}-\mathrm{Zn}$ alloys [73]. Now it is an established topic for investigations and the instrument for the tailoring the properties of materials [76]. Below, the decomposition of the solid solution in all discussed cases leads to the formation of small particles of the second phase (i.e. to precipitation). Therefore, for this discussion we use the terms "decomposition" and "precipitation" as synonyms.

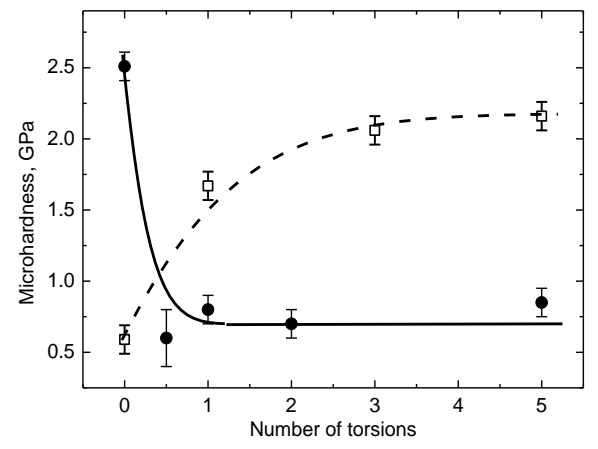

Fig. 3 Vickers microhardness plotted vs. number of torsions for pure $\mathrm{Al}-30 \mathrm{wt}$. $\% \mathrm{Zn}$ (filled circles) [31] and Al- 8.8 wt. \% Mg alloys (open squares) [55]

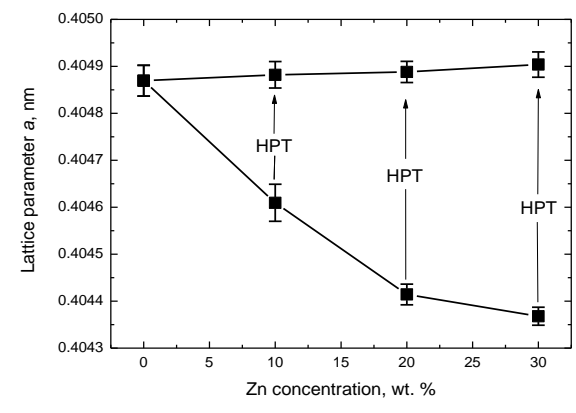

Fig. 4 Dependence of the lattice parameter in aluminium matrix on the total zinc concentration in the Al-Zn alloys before and after HPT [73]

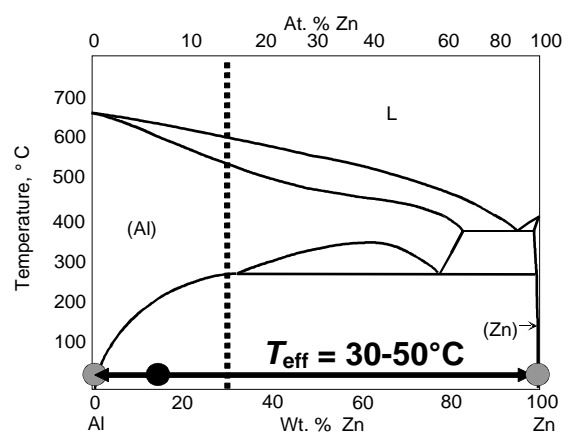

Fig. 5 Al-Zn phase diagram. Vertical dotted line shows the composition of Al30 wt. \% $\mathrm{Zn}$ alloy. Large black circle shows the composition of supersaturated (Al) solid solution in coarse-grained $\mathrm{Al}-30 \mathrm{wt}$. \% $\mathrm{Zn}$ alloy before HPT (it contained 15 wt. \% Zn). Large grey circles show the composition of phases in ultra-fine-grained $\mathrm{Al}-30 \mathrm{wt}$ \% $\mathrm{Zn}$ alloy after HPT [73]. The value of $\mathrm{T}_{\text {eff }}=30-50^{\circ} \mathrm{C}$ is also given 
The as-cast Al-Zn alloys were subjected to HPT at 5 turns, 5 GPa and $1 \mathrm{rpm}$ [73]. The coarsegrained supersaturated solid solution $(\mathrm{Al})$ in the as-cast $\mathrm{Al}-30 \mathrm{wt} . \% \mathrm{Zn}$ alloy contained about 15 wt.\% Zn. Zn concentration in the solid solution for $\mathrm{Al}-20 \mathrm{wt}$. \% $\mathrm{Zn}$ and $\mathrm{Al}-10$ wt. \% $\mathrm{Zn}$ alloys (measured locally by the electron-probe microanalysis) was 7 and $3 \mathrm{wt} . \% \mathrm{Zn}$, correspondingly. In Fig. 4 the respective values for the lattice parameter in (Al) are given, they are well below the lattice parameter in pure aluminium. The HPT at room temperature produced nanograined pure $\mathrm{Al}$ and pure $\mathrm{Zn}$ particles [20, 73]. The supersaturated solid solution also completely decomposed, and the lattice parameter in all three alloys became non-distinguishable from that of pure aluminium (Fig. 4). The composition of the solid solutions in $\mathrm{Al}-30 \mathrm{wt}$. \% Zn before and after the HPT is shown by black and grey circles in Fig. 5 correspondingly. The decomposition during SPD proceeds extremely quickly. Already after about 0.5 rotations of anvils the lattice spacing becomes equal to that of $\mathrm{Al}$ and microhardness reaches its steady-state value [73].

The competition between dissolution of precipitates and decomposition of supersaturated solid solution has been studied in details for the binary copper alloys [6]. Physically, it is the steadystate concentration in the solid solution $c_{\mathrm{ss}}$ which establishes during SPD. However, in order to compare different binary alloys with different maximal solubilities of a second component, an idea of a so-called effective temperature $T_{\text {eff }}$ is very useful. Thus, after SPD the concentration $c_{\mathrm{ss}}$ of a second component in the matrix solid solution is as high as if the sample has been annealed

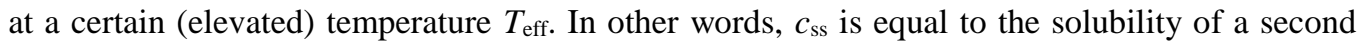
component at $T_{\text {eff. }}$ The solubility is defined by the solvus line in the equilibrium binary phase diagram.

Consider the example of competition between dissolution and precipitation in $\mathrm{Cu}-\mathrm{Co}$ system [32, 77, 78]. The as cast $\mathrm{Cu}-4.9$ wt. \% Co alloy contained grains of $\mathrm{Cu}$-based solid solution (with grain size $10-20 \mu \mathrm{m}$ ), Co particles with size about $2 \mu \mathrm{m}$ and fine dispersed Co precipitates with a size about $10-20 \mathrm{~nm}[32,77,78]$. Cobalt fully dissolved in copper matrix after annealing at $1060^{\circ} \mathrm{C}$ for $10 \mathrm{~h}$ (sample 2). The grain size after this annealing was about $50 \mu \mathrm{m}$. During annealing at $570^{\circ} \mathrm{C}$ for $840 \mathrm{~h}$ (sample 1), the $\mathrm{Cu}$-based solid solution almost fully decomposed: less than 0.5 wt. \% Co remained dissolved in $\mathrm{Cu}$ (based on XRD measurements and phase diagram [29]).

After HPT of both samples the $\mathrm{Cu}$ grain size drastically decreased to about $200 \mathrm{~nm}$, and that of Co-precipitates to only 10-20 nm (insets in Fig. 6). The lattice parameter of Sample 1 before deformation is very close to that of pure copper (diamond in Fig. 6). With an increasing number of rotations, the lattice parameter of Sample 1 decreased and that of Sample 2 increased. After 5 anvil rotations (1800 deg.) the lattice parameter in both samples becomes almost undistinguishable and corresponds to the solid solution of $\mathrm{Co}$ in $\mathrm{Cu}$ with nearly $2.5 \mathrm{wt} . \%$. In other words, the composition of the solid solution in the $\mathrm{Cu}-4.9$ wt. \% Co alloy after HPT does not depend on the initial state prior to HPT. This is a so-called equifinal composition $c_{\mathrm{eq}} \approx 2.5 \mathrm{wt}$. $\% \mathrm{Co}$. Thus, the steady-state with respect to the grain size, size of Co precipitates, torsion torque and concentration of $\mathrm{Co}$ in a solid solution during HPT is indeed equifinal. The composition of $\mathrm{Cu}$-rich matrix in both alloys before and after HPT is shown in the $\mathrm{Cu}-\mathrm{Co}$ phase diagram (Fig. 7). The solid solution in samples 1 and 2 after HPT contains as much $\mathrm{Co} c_{\mathrm{eq}} \approx 2.5 \mathrm{wt} . \% \mathrm{Co}$, as if they would be annealed at $T_{\text {eff } 1}=920 \pm 30^{\circ} \mathrm{C}$ and $T_{\text {eff } 2}=870 \pm 30^{\circ} \mathrm{C}$, respectively.

Here the analogy appears between thermodynamic equilibrium when the composition of phases does not depend on the starting state and equifinality when the composition of phases in a steadystate during SPD also does not depend on the phases in a starting state. The values like equivalent (effective) temperature $T_{\text {eff }}$ and steady-state (equifinal) composition of solid solution $c_{\text {eq }}$ are frequently called attractors in the thermodynamics of non-equlibrium (or open) systems [79]. 


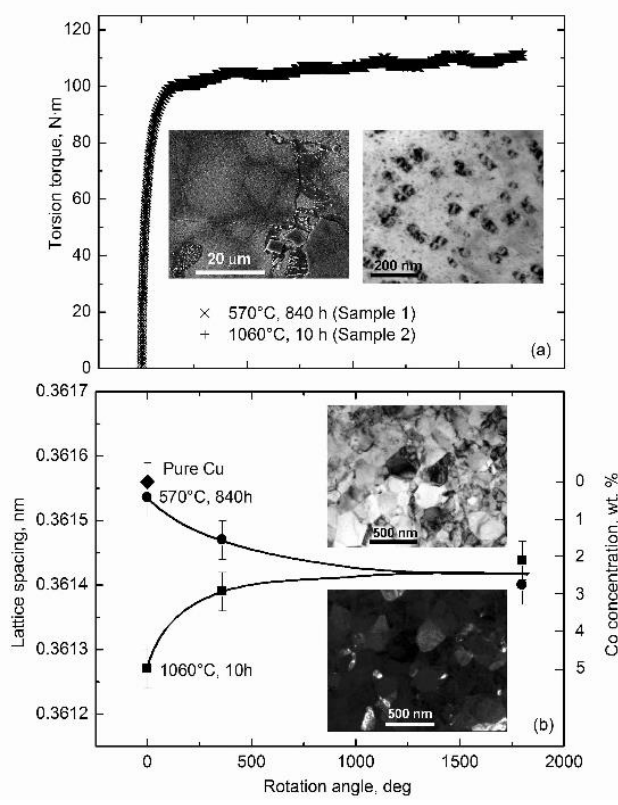

Fig. 6 (a) Dependence of torsion torque on the rotation angle. Insets: SEM (left) and bright-field TEM (right) micrographs of $\mathrm{Cu}-4.9$ wt. \% Co alloy after annealing at $570^{\circ} \mathrm{C}$ for $840 \mathrm{~h}$. (b) Dependence of lattice spacing on the rotation angle. Circles mark the lattice spacing in Sample 1 annealed at $570^{\circ} \mathrm{C}$ for $840 \mathrm{~h}$. Squares correspond to the Sample 2 annealed at $1060^{\circ} \mathrm{C}$ for $10 \mathrm{~h}$. Diamond shows the lattice spacing for pure copper. The respective Co concentration is shown on the right vertical axis, $\mathrm{c}_{\mathrm{eq}} \approx 2.5 \mathrm{wt}$ \% $\%$ Co. Insets: Bright-field (top) and dark-field (bottom) TEM micrographs of $\mathrm{Cu}-4.9$ wt. \% Co alloy after annealing at $570^{\circ} \mathrm{C}$ for $840 \mathrm{~h}$ and HPT (6 GPa, 5 rot, $1 \mathrm{rpm})$ [32]

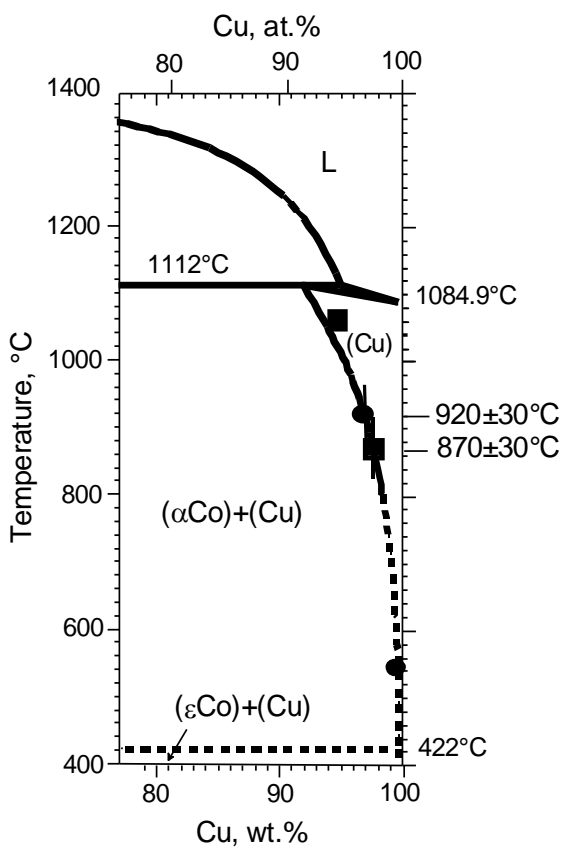

Fig. 7 The $\mathrm{Cu}$-rich part of the $\mathrm{Co}-\mathrm{Cu}$ phase diagram [29]. The composition of $\mathrm{Cu}$-rich matrix in both alloys before and after HPT is shown. Circles mark the data for Sample 1 annealed before HPT at $570^{\circ} \mathrm{C}$. Squares correspond to the Sample 2 annealed before $\mathrm{HPT}$ at $1060^{\circ} \mathrm{C}$ [31]. Steady-state (equifinal) composition of solid solution $\mathrm{c}_{\mathrm{eq}}$ is about $2.5 \mathrm{wt}$ \% C [32]

In [6] the values of $T_{\text {eff }}$ were compared for several $\mathrm{Cu}$-based alloys $\mathrm{Cu}-\mathrm{Ni}$ [80], $\mathrm{Cu}-\mathrm{Co}[32,77$, 78], $\mathrm{Cu}-\mathrm{Sn}$ [81-83], $\mathrm{Cu}-\mathrm{In}$ [84, 85], $\mathrm{Cu}-\mathrm{Cr}$ [86], $\mathrm{Cu}-\mathrm{Ag}$ [87-89], $\mathrm{Cu}-\mathrm{Al}-\mathrm{Ni}$ [90, 91] Cu-Hf [6] (Fig. 8). The $T_{\text {eff }}$ linearly increases with increase of activation enthalpy of bulk tracer diffusion $H_{\mathrm{D}}$. The correlation between activation enthalpy of bulk tracer diffusion $H_{\mathrm{D}}$ and melting 
temperature $T_{\mathrm{m}}$ of diffusing alloying component also has been found. As a result, $T_{\text {eff }}$ linearly increases with increase of melting temperature $T_{\mathrm{m}}$ of diffusing alloying component as well. The observed correlations allow one to predict the behaviour and phase transitions in the $\mathrm{Cu}$-based alloys under high pressure torsion.
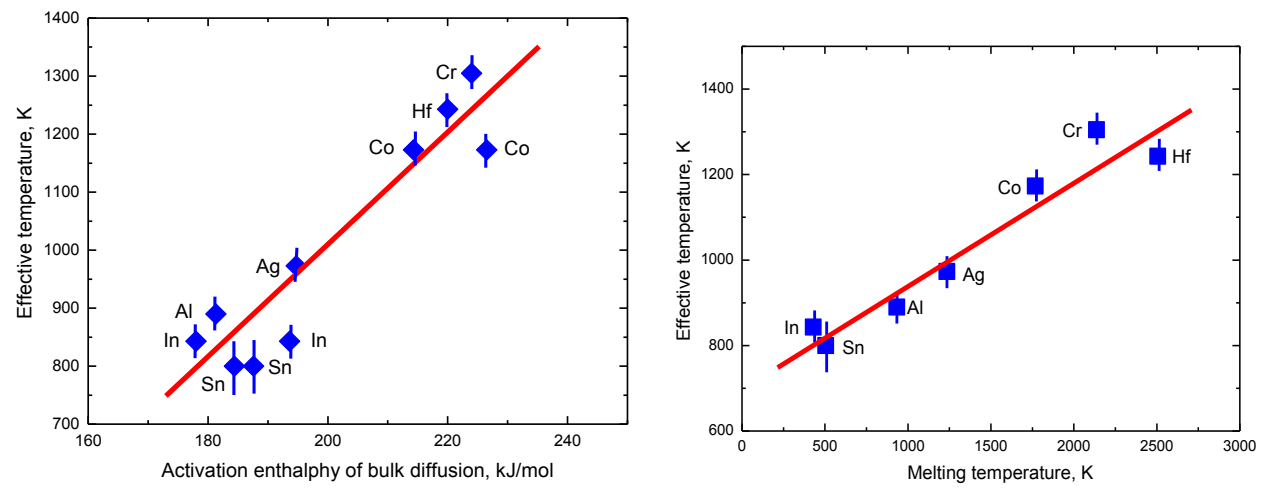

Fig. 8 (a) Dependence between effective temperature of HPT treatment $T_{\text {eff }}$ of copperbased solid solutions and activation enthalpy of bulk tracer diffusion $H_{\mathrm{D}}$ of alloying element [6]. (b) Correlation between effective temperature $T_{\text {eff }}$ and melting temperature $T_{\mathrm{m}}$ of alloying element in various Cu-based alloys. The values of $H_{\mathrm{D}}$ and $T_{\mathrm{m}}$ were taken from the handbook [85]

\section{Amorphization and nanocrystalisation}

SPD produces high amount of defects, thus the material is very far from equilibrium during SPD. Nevertheless, one can use the equilibrium phase diagrams as an instrument for the description of phase transformations in the non-equilibrium conditions. This idea goes back to the work of Georges Martin who developed it for the description of phase transformations under strong irradiation [92]. His main idea was that the forced mixing induced by irradiation emulates the increase of entropy and changes the thermodynamic potentials in the alloy. The equilibrium configuration of the solid under irradiation flux $\varphi$ at temperature $T$ is identical to the configuration at $\varphi=0$ and a certain effective temperature $T_{\text {eff: }}$ :

$T_{\text {eff }}=T(1+\Delta)$

If the irradiation-driven movements of atoms are similar in amplitude to conventional diffusion jumps, they can be described by the "ballistic" diffusion coefficient $D_{\text {ball }}$ and $\Delta=D_{\text {ball }} / D_{\mathrm{b}}$, where $D_{\text {b }}$ is conventional bulk diffusion coefficient, possibly increased due to the non-equilibrium defect concentration [92]. It means that one can use the equilibrium phase diagram for the description of the system under irradiation, but at $T_{\text {eff }}$ instead of the actual temperature $T$. For example, if the liquid phase is present in the phase diagram at $T_{\text {eff, }}$, the amorphous phase would appear under irradiation [92]. Thus, G. Martin proposed to find a temperature $T_{\text {eff }}$ (usually called effective temperature) in an equilibrium phase diagram where the given phase appears under irradiation. The composition of phases after SPD allows to localize those phases in the respective equilibrium phase diagram and to estimate the effective temperature $T_{\text {eff. }}$ Such a schematic diagram is shown in Fig. 9. We already used this idea for description of the SPD influence (see Section 3). In our case we use the value of $D_{\text {HPT }}$ for the diffusion-like mass-transfer induced by HPT instead of $D_{\text {ball }}$. 
The obvious example for the $T_{\text {eff }}$ approach is the amorphization. Let us consider first the HPT of $\mathrm{Nb}-\mathrm{Ni}-\mathrm{Y}$ alloys $[93,94]$. The coarse-grained as-cast $\mathrm{Ni}-20 \mathrm{wt} . \% \mathrm{Nb}-30 \mathrm{wt} . \% \mathrm{Y}$ and $\mathrm{Ni}-18 \mathrm{wt} . \%$ $\mathrm{Nb}-22$ wt. $\% \mathrm{Y}$ alloys contained before high pressure torsion (HPT) the $\mathrm{NiY}, \mathrm{NbNi}_{3}, \mathrm{Ni}_{2} \mathrm{Y}, \mathrm{Ni}_{7} \mathrm{Y}_{2}$ and $\mathrm{Ni}_{3} \mathrm{Y}$ phases (point $g$, Fig. 9) (Fig. 10a) [95, 96]. After HPT these alloys transformed into a mixture of two nanocrystalline $\mathrm{NiY}$ and $\mathrm{Nb}_{15} \mathrm{Ni}_{2}$ phases and two different amorphous phases (one was $\mathrm{Y}$-rich and another $\mathrm{Nb}$-rich) (point 6, Fig. 9). The $\mathrm{Ni}-\mathrm{Nb}-\mathrm{Y}$ phase diagram contains two immiscible melts above $1440^{\circ} \mathrm{C}$ (Fig. 10a) [96]. Therefore, the effective temperature is slightly above $T_{\mathrm{e}}=1440^{\circ} \mathrm{C}$ and can be estimated as $T_{\text {eff }}=1450^{\circ} \mathrm{C}$ (Fig. 10a). It is remarkable that the rapid solidification of these alloys from the liquid state (point $f$, Fig. 9) also allows obtaining the mixture of two amorphous phases.

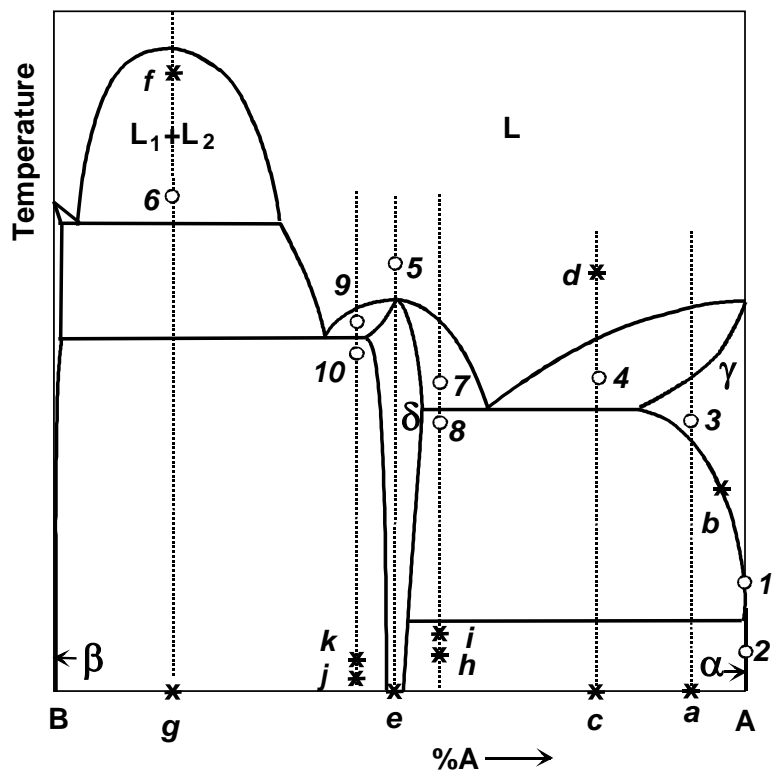

Fig. 9 The schematic binary phase diagram showing the points of HPT deformation or other thermal treatments (stars) and respective configuration points at the (increased) effective temperatures. The dashed vertical lines denote compositions of various alloys. Figurative points corresponding to the effective temperature of the alloys are indicated by an open circle and numbered. Each star point with a letter indicates the composition and temperature of an alloy's treatment (normal cooling, SPD or rapid quenching)

In $[7,8]$ the HPT has been used for the treatment of liquid-phase sintered hard magnetic NdFeBbased alloy ( $5 \mathrm{GPa}, 1 \mathrm{rpm}, 5$ rot, ambient temperature). The amorphization of the crystalline alloy took place under the action of HPT. This permitted to obtain for the first time the mixture of two different amorphous phases with embedded grains of the ferromagnetic $\mathrm{Nd}_{2} \mathrm{Fe}_{14} \mathrm{~B}$ phase. The SPD-treatment at ambient temperature $T_{\mathrm{SPD}}=300 \mathrm{~K}$ is frequently equivalent to the heat treatment at a certain elevated temperature $T_{\text {eff }}>300 \mathrm{~K}$. The composition of phases in the studied NdFeBbased alloy after HPT corresponds to the state at $T_{\text {eff }} \sim 1170^{\circ} \mathrm{C}$ (Fig. 11). 


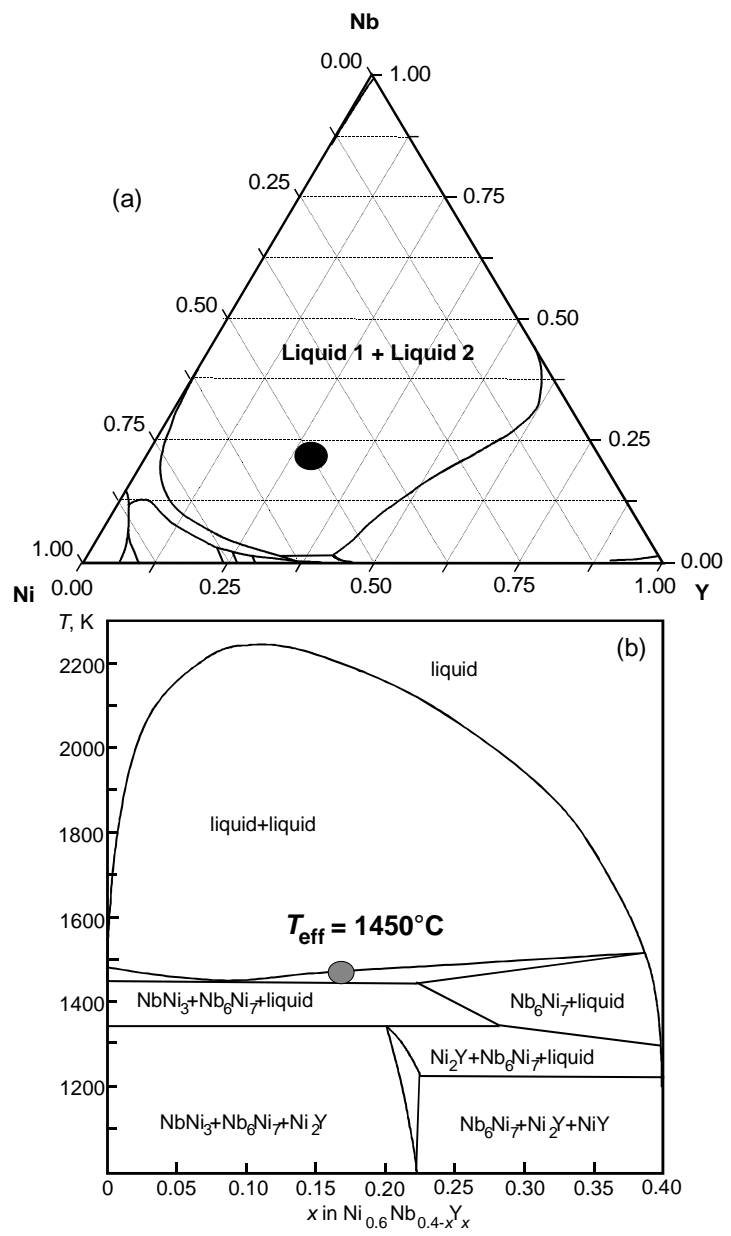

Fig. 10 (a) Liquidus projection obtained by the CALPHAD method of the $\mathrm{Y}-\mathrm{Ni}-\mathrm{Nb}$ ternary phase diagram at [95]. The composition of the triple $\mathrm{Ni}_{50} \mathrm{Nb}_{20} \mathrm{Y}_{30}$ alloy used for HPT investigations is marked by the large black circle. (b). Calculated pseudo-binary section of the ternary phase diagram $\mathrm{Ni}_{60} \mathrm{Y}_{40}-\mathrm{Ni}_{60} \mathrm{Nb}_{40}$ [96]. Large grey circle shows the composition of phases in ultra-fine-grained alloy after HPT (two amorphous phases and two crystalline ones). The value of $T_{\text {eff }}=400^{\circ} \mathrm{C}$ is also given

Especially valuable data on the effective temperature at SPD can be extracted from the results on HPT treatment of Ti-48.5 at.\% Ni, Ti-50.0 at.\% Ni and Ti-50.7 at.\% Ni alloys [97]. The HPT of equiatomic Ti-50.0 at.\% $\mathrm{Ni}$ alloy at room temperature (point $e$, Fig. 9) resulted in the fully amorphous state (point 5, Fig. 9, $T_{\text {eff }}=1350^{\circ} \mathrm{C}$, respectively). The HPT of the non-equiatomic Ti48.5 at.\% Ni alloy at $270^{\circ} \mathrm{C}$ (point $h$ ) produced the mixture of amorphous and nanocrystalline phases (point $7, T_{\text {eff }}=1050^{\circ} \mathrm{C}$ ). When the HPT temperature of the Ti-48.5 at. $\%$ Ni alloy increased up to $350^{\circ} \mathrm{C}$ (point $h$ ), only the mixture of nanocrystaline phases formed, without amorphous phase. It means that the corresponding point moved from the position 7 in the $\delta+\mathrm{L}$ region into position 8 in the two-phase $\delta+\gamma$ region and the effective temperature decreased to $T_{\text {eff }}=950^{\circ} \mathrm{C}$. 
The HPT of another non-equiatomic Ti-50.7 at.\% Ni alloy at $200^{\circ} \mathrm{C}$ (point $j$ ) produced the mixture of amorphous and nanocrystalline phases (point $9, T_{\text {eff }}=1250^{\circ} \mathrm{C}$ ). When the HPT temperature of the $\mathrm{Ti}-50.7$ at. $\% \mathrm{Ni}$ alloy increased up to $250^{\circ} \mathrm{C}$ (point $k$ ), only the mixture of nanocrystaline phases formed, without amorphous phase. It means that the corresponding point moved from the position 9 in the $\delta+\mathrm{L}$ region into position 10 in the two-phase $\delta+\beta$ region and the effective temperature decreased to $T_{\text {eff }}=1100^{\circ} \mathrm{C}$. Therefore, it can be clearly seen from the data obtained by Prokoshkin et al. [97] that the increase of the HPT treatment temperature leads to the decrease of $T_{\text {eff. It }}$ is in full accordance with the equation (1) because the increase of $T$ leads to increase of $D_{\mathrm{b}}$, and at the same time the amount of deformation-driven atomic movements characterized by $D_{\text {HPT }}$ remains unchanged. Other examples of amorhization under the action of SPD can be found in Refs. [98-103]. Nanocrystallization is a process which is opposite to the amorphization. If one applies SPD to the initially amorphous sample, one can observe that the small nanocrystals start to appear [104-112]. Obviously, the nanocrystallization and amorphization are also coupled and competing processes like precipitation/dissolution (see Section 3 above).

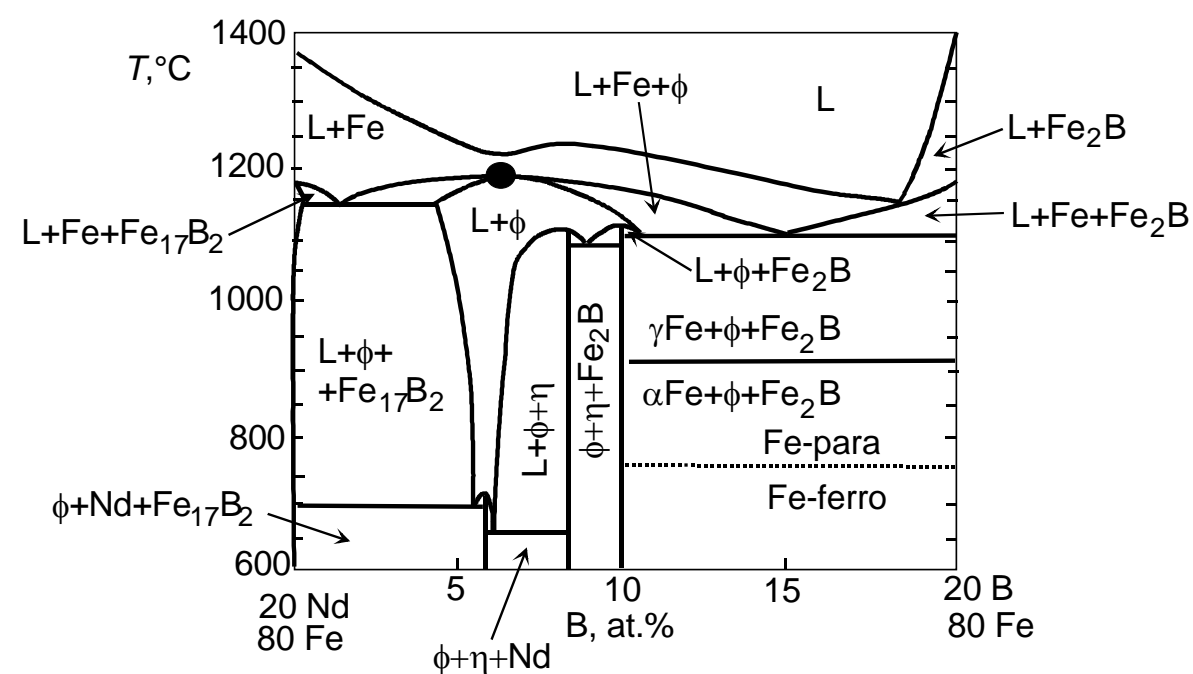

Fig. 11 The 80 at.\% Fe section of the $\mathrm{Fe}-\mathrm{Nd}-\mathrm{B}$ phase diagram. Large filled circle shows the effective temperature $T_{\text {eff }}=1170 \pm 30^{\circ} \mathrm{C}[7,8]$

\section{SPD-driven accelerated mass-transfer}

The discussed SPD-driven phase transformations are connected with redistribution of components and, therefore, with mass transfer. This SPD-driven mass transfer is diffusion-like, in other words by the SPD-driven jump of an atom from one lattice position to another this atom has to overcome the same energetic barrier as during the conventional diffusion.

In $[87,80]$ we developed a mass-transfer model for the description of dynamic equilibrium in competitive precipitation and dissolution by the HPT in copper-silver system. This model assumes that HPT fixes the composition at interfaces between copper matrix and silver precipitate. It has been shown that the observed steady-state composition in the matrix and precipitate size are controlled by the HPT-enhanced diffusion-like mass-transfer. We succeeded to calculate the steady-state concentration $c_{\mathrm{ss}}$ using only the value of bulk diffusion coefficient $D$. Afterwards we found the $T_{\text {eff }}$ value supposing that $c_{\mathrm{ss}}$ is equal to the silver solubility in copper at $T_{\text {eff. }}$ As in the cases discussed above in Sections 3 and 4, $T_{\text {eff }}$ in $\mathrm{Cu}-\mathrm{Ag}$ alloys was higher than the HPT 
temperature $T_{\mathrm{HPT}}$. The fact that usually $T_{\mathrm{eff}}>T_{\mathrm{HPT}}$ means simply that the steady-state concentration of vacancies during HPT is higher than the equilibrium one at $T_{\text {HPT. }}$ It could be close to the equilibrium vacancy concentration at $T_{\text {eff }}[113,114]$.

If one substitutes cobalt or silver in the copper-based solid solution, the bulk diffusion coefficient $D$ of an impurity also changes. According to the Eq (1), the higher $D$ would lead to the lower $T_{\text {eff }}$ and lower $D$ requires higher $T_{\text {eff. }}$ Fig. 8a contains the plot showing nearly linear correlation between activation enthalpy of bulk diffusion $H_{\mathrm{D}}$ and $T_{\text {eff. }}$. Physically, such correlation is easy to understand because the high $H_{\mathrm{D}}$ means also high energy barrier for the jumps of alloying atoms between lattice positions in copper. Increased energy barrier for atomic jumps decreases the diffusivity and relaxation rate in the dynamic equilibrium between precipitation and dissolution during HPT. In turn, slow relaxation, increases the steady-state concentration of non-equilibrium lattice defects (vacancies). As a result, $T_{\text {eff }}$ would increase as well.

The SPD-driven mass transfer proceeds extremely quickly and in ambient conditions without substantial increase of sample temperature [115]. Usually, the time for establishment of steadystate by HPT is about 2-5 minutes. It varies by change of pressure, strain rate and HPT temperature, but not more than one order of magnitude. One can estimate the observed SPDdriven mass-transfer using the effective diffusion coefficient and compare it with "conventional" diffusion coefficients at temperature of HPT-treatment and at $T_{\text {eff. }}$.

The SPD-driven phase transformations can also be analyzed when assuming [1] that the steadystate concentration of lattice defects during SPD is higher than that in the equilibrium at the temperature of SPD-treatment, $T_{\mathrm{SPD}}$, and pressure of the SPD-treatment, $P_{\mathrm{SPD}}$. It has been indeed observed in the direct measurements of vacancy concentration during HPT $[115,117]$. This concentration would be equal to the equilibrium concentration of lattice defects at a certain effective temperature $T_{\text {eff }}$ [1]. In case of Cu-Co system $T_{\text {eff }}$ amounts to $T_{\text {eff }}=900^{\circ} \mathrm{C}$ (Fig. 7). Fig. 7 shows the composition of $\mathrm{Cu}$-rich matrix in both alloys before and after HPT in the $\mathrm{Cu}-\mathrm{Co}$ phase diagram. The $\mathrm{Cu}$-rich solid solution in both alloys after HPT contains as much $\mathrm{Co} c_{\mathrm{eq}} \approx 2.5 \mathrm{wt}$. \% Co, as if they would be annealed at $T_{\text {eff }}=900^{\circ} \mathrm{C}$.

The extrapolation of bulk diffusion coefficients to $T_{\text {eff }}$ gives $D=5 \times 10^{-14} \mathrm{~m}^{2} / \mathrm{s}$ for diffusion of Co in $\mathrm{Cu}$ [118] and $D=10^{-13} \mathrm{~m}^{2} / \mathrm{s}$ for self-diffusion in $\mathrm{Cu}$ [119]. Indeed, the deformation driven mechanisms can ensure the mass-transfer rate which is comparable to the bulk diffusion fluxes at $T_{\text {eff }}=900^{\circ} \mathrm{C}$. The bulk diffusion fluxes at $900^{\circ} \mathrm{C}$ could ensure the decomposition/precipitation rates even if the effect of pressure is taken into account $[120,121]$.

\section{Allotropic and martensitic transformations}

Many elements exist in different allotropic modifications at different temperature and pressure. The most prominent examples are iron, cobalt, titanium. For example, the $\mathrm{Co}-\mathrm{Cu}$ alloys before HPT contain the (metastable at room temperature) fcc $\alpha$-Co phase, but after HPT the $\varepsilon$-Co phase appears in the samples $[1,59,60,122]$. Even more interesting is the situation in $\mathrm{Ti}, \mathrm{Zr}$ and $\mathrm{Hf}$ where the high-pressure $\omega$-phase exists [123]. The $\mathrm{Ti}, \mathrm{Zr}$ and $\mathrm{Hf}$ possess also two different allotropic modifications at ambient pressure, namely the low-temperature hep $\alpha$-phase and hightemperature $\beta$-phase. HPT leads to the transitions of $\alpha$ - and $\beta$-phases to the $\omega$-phase which remain in the samples after pressure release [123-126]. The alloying of titanium with $\beta$-stabilizers (like $\mathrm{Fe}, \mathrm{Co}$ or $\mathrm{Nb}$ ) strongly modifies the $\alpha$ - $\beta$ - $\omega$-transformations [126-130]. For example, the $\beta$-to- $\omega$ transformation in Ti-alloys is martensitic [126-128]. There are special orientation relationships between $\beta$ and $\omega$ lattices which ensure the diffusionless martensitic transformations where long- 
range mass transfer is not needed and the atoms conserve more or less their neighbors before and after transition [131]. It has been observed, for example, that iron addition changes the lattice parameters in $\beta$ and $\omega$ phases in such a way that in the $\mathrm{Ti}-4$ wt. $\% \mathrm{Fe}$ alloy the orientation relationship fulfils optimally. At this concentration the amount of $\omega$ phases transformed from the $\beta$ one reaches almost $100 \%$ and decreases by lower and higher Fe concentration $[126,127]$. The metastable $\omega$-phase disappears by heating around $150^{\circ} \mathrm{C}$ in pure titanium. However, the alloying can stabilize it up to $500^{\circ} \mathrm{C}[131,132]$.

HPT of silicon and germanium also leads to the formation of metastable high pressure phases $[133,134]$. In [135] the single crystalline $\mathrm{Si}(100)$ was subjected to HPT at $24 \mathrm{GPa}$ at room temperature. The HPT-processed samples contained lattice defects such as dislocations and nanotwins in diamond-cubic Si-I, and metastable phases such as body-centered-cubic Si-III and hexagonal-diamond Si-IV. In [134] crystalline Ge disks were subjected to HPT under the nominal pressure of $24 \mathrm{GPa}$. The samples processed at room temperature consisted of diamond-cubic GeI and simple tetragonal Ge-III nanograins in addition to amorphous regions. The samples processed at $77 \mathrm{~K}$ consisted of Ge-I as well as residual Ge-III nanograins and some amorphous phase. No other metastable phases such as body-centered-cubic Ge-IV or hexagonal-diamond Ge$\mathrm{V}$ were observed in the cryogenic HPT-processed sample.

Similar to the semiconductors $\mathrm{Si}$ and Ge, plastic deformation of oxides is generally very difficult due to their hard and brittle nature resulting from their covalent or ionic bonding. However, the HPT technique allows one to keep the silicon, germanium or oxide samples in the confined space, the samples cannot break or "escape" from the volume between the HPT anvils. This unique feature allows one to reach the high strains in the oxides. Moreover, one can start from powder samples. HPT first compact the powder and then ensures the deformation. Thus, the opportunity to strain oxides and/or metal/oxide composites is very general [136]. However, here we discuss only the cases where oxides possess different crystal lattices and respective phase transitions can take place.

Crystalline $\mathrm{VO}_{2}$ transformed from the coarse-grained monoclinic phase to a nanograined triclinic phase with insulating electrical properties by plastic strain effect [137]. The anatase-to-rutile phase transformation in $\mathrm{TiO}_{2}$ usually occurrs at $1173 \mathrm{~K}$. During HPT of titania ceramic nanopowder the anatase-to-rutile transformation took place at 473-573 K [138]. The formation of rutile phase was accompanied with dynamic recrystallization and an unusual grain growth. A high-pressure $\mathrm{TiO}_{2}-$ II phase (columbite) with the orthorhombic structure was formed by HPT under pressures of 1 and $6 \mathrm{GPa}$. Fraction of $\mathrm{TiO}_{2}-\mathrm{II}$ increased with increasing the plastic strain and remained stable at ambient pressure. $\mathrm{TiO}_{2}$-II was stabilized in grains with sizes less than $\sim 15 \mathrm{~nm}$ because of high energy barrier for reverse phase transformation, while larger grains had the anatase structure [139]. Barium titanate, $\mathrm{BaTiO}_{3}$ belongs to the group of perovskite oxides with the general $\mathrm{ABO}_{3}$ formula. $\mathrm{BaTiO}_{3}$ transforms under ambient pressure from a rhombohedral structure to an orthorhombic phase at $-90^{\circ} \mathrm{C}$, to a ferroelectric tetragonal phase at $5^{\circ} \mathrm{C}$, and to a paraelectric cubic phase at $120^{\circ} \mathrm{C}$ [140-143]. At ambient temperature, it exhibits a tetragonal-to-cubic phase transformation at $2 \mathrm{GPa}$ [140-143] and it disorders at $5 \mathrm{GPa}$ [144]. HPT of tetragonal $\mathrm{BaTiO}_{3}$ powders leads to the formation of cubic phase and to strong grain refinement [145].

$\mathrm{ZrO}_{2}$ has a monoclinic phase at room temperature under ambient pressure, and transforms to a tetragonal phase at $1373 \mathrm{~K}$, a cubic phase at $2673 \mathrm{~K}$, a liquid phase at $2963 \mathrm{~K}$ and an orthorhombic phase under pressures above $10 \mathrm{GPa}$ [146]. However, addition of specific elements such as $\mathrm{Y}$ to $\mathrm{ZrO}_{2}$ stabilizes the tetragonal phase at room temperature [147]. This partially stabilized $\mathrm{ZrO}_{2}$ 
exhibits a phase transformation from tetragonal to monoclinic [148]. During HPT the transformation with a coherent interface occurs from the metastable tetragonal phase to the monoclinic phase [149].

\section{Grain boundary phase transitions}

Severe plastic deformation drives not only phase transformations between 3-dimensional or bulk phases discussed above. SPD can also lead to the various grain boundary (GB) phase transitions. The most prominent GB phase transformations like wetting-dewetting ones take place in the twophase (or multiphase) regions of the bulk phase diagrams [150]. In case of complete wetting, the second phase (liquid or even solid one) forms the continous layer between two grains in the matrix $[13,24,151]$. In this case the contact angle between GB and second phase is zero [152]. In case of incomplete (or partial) wetting, the second phase (liquid or solid) forms the chain of individual particles along GB with a certain non-zero contact angle [153,154]. If the amount of wetting phase is small, the continous layer between two grains can become very thin, it contains few monolayers of a second component and is just a couple of nanometers thick [155-157]. If the amount of a second component in GB is below one monolayer, one speaks about conventional GB adsorption $[157,158]$. If the GB contact angle is high, but the GB between individual particles of a second phase contains few monolayers of a second component, one speaks about pseudopartial (or psedoincomplete, or constrained complete) GB wetting [159-161]. The transitions between these different GB states (phases) are called GB transitions, and they also can be driven by SPD, similar to the bulk (or volume) ones.

The grain size after SPD is very small. In other words, the specific area of grain boundaries in a volume unit increases. Therefore, the "conventional" grain boundary phase transitions become more pronounced then in the coarse-grained materials. For example, the usage of the ultrafinegrained polycrystals made it possible to observe and measure the thermal effect of the GB premelting phase transformations [162-165]. In other words, the liquid-like GB layers form well below the bulk solidus line. As a result, the melting in GBs begins during heating $10-15{ }^{\circ} \mathrm{C}$ earlier than in the bulk [162-165]. Between bulk and GB solidus the (generally solid) polycrystal contains thin liquid GBs. Such a materials possesses extremely high plasticity [166-170]. The high specific density of GBs in the SPD-treated alloys allowed one also to observe the thermal effect of phase transition from incomplete to complete GB wetting [163-165]. It takes place between bull solidus and liquidus lines.

Even in case of one-layer GB adsorption (i.e. when the concentration of a second component per GB unit area is below one monolayer), the specific area of GBs in SPD-treated polycrystals is so high that a big amount of a second component is needed to fill all GB adsorption layers. These adsorbed GB atoms are taken away from the bulk second phase. As a result, the amount of bulk second phase decreases, it can disappear completely (like, for example, disappears cementite in steels). In such a way, the GB adsorption can apparently shift the lines in the bulk phase diagrams for the ultra-fine grained materials in comparison with their coarse-grained counterparts [170173].

The HPT of the Al-Zn, Al-Mg and Al-Zn-Mg alloys leads to the formation of 2-5 nm thin GB layers of $\mathrm{Zn}$-rich phase [75, 174-182]. The contact angle between $\mathrm{Zn}$ particles and GB is high, the GB between individual particles of a second phase contains few monolayers of a second component. In other words, here one can speaks about pseudopartial GB wetting [159-161]. The presence of "soft" Zn-rich GB layers between grains of "hard" phase leads to a kind of lubricating 
during GB sliding. As a result, the ultrafine-grained Al-based alloys become superductile [175177, 179-182]. The opposite effect can also take place. Thus, the second solid phase can form before HPT the continous layers in GBs of a matrix (so-called complete GB wetting). If this phase is hard (like for example in case of $\mathrm{Cu}-\mathrm{Sn}$ or $\mathrm{Mg}$-based alloys), the soft matrix deform during HPT and its grains are refined, but the hard skeleton of intermetallics in the initial GBs remain more or less intact and ensure the high hardness of an alloy [13, 24, 76, 79]. All these SPD-driven GB phenomena are now under intensive investigations.

\section{Conclusions}

It is frequently observed that the phases in the materials after severe plastic deformation differ from those in the initial state. During SPD established a steady-state, and structure and properties of a material in this steady state do not depend on the initial state and are, therefore, equifinal. The SPD-induced phase transformations proceed very quickly, they include precipitation and dissolution of precipitates, amorphization and (nano) crystallization, allotropic and martensitic transitions and formation of grain boundary phases.

\section{References}

[1] B. B. Straumal, A.A. Mazilkin, B. Baretzky, E. Rabkin, R.Z. Valiev: Materials Transactions, Vol. 53, 2012, p. 63-71, https://doi.org/10.2320/matertrans.MD201111

[2] X. Sauvage, A. Chbihi, X. Quelennec: Journal of Physics, Vol. 240, 2010, p. 012003, https://doi.org/10.1088/1742-6596/240/1/012003

[3] B. Straumal, A. Korneva, P. Zięba: Archives of Civil and Mechanical Engineering, Vol. 14, 2014, p. 242-249, https://doi.org/10.1016/j.acme.2013.07.002

[4] E. I. Teitel', L. S. Metlov, D. V. Gunderov, A. V. Korznikov: Physics of Metals and Metallography 113, 2012, p. 1162-1168, https://doi.org/10.1134/S0031918X12120095

[5] B. B. Straumal et al.: International Journal of Materials Research, Vol. 106, 2015, p. 657664, https://doi.org/10.3139/146.111215

[6] B. B. Straumal, A. R. Kilmametov, A. Korneva, A. A. Mazilkin, P. B. Straumal, P. Zięba, B. Baretzky: Journal of Alloys and Compounds, Vol. 707, 2017, p. 20-26, https://doi.org/10.1016/j.jallcom.2016.12.057

[7] B. B. Straumal et al.: Materials Letters, Vol. 145, 2015, p. 63-66, https://doi.org/10.1016/j.matlet.2015.01.041

[8] B. B. Straumal, A. A. Mazilkin, S. G. Protasova, D. V. Gunderov, G. A. López, B. Baretzky: Materials Letters, Vol. 161, 2015, p. 735-739, https://doi.org/10.1016/j.matlet.2015.09.076

[9] C. Borchers et al.: Acta Materialia, Vol. 97, 2015, p. 207-215, https://doi.org/ 10.1016/j.actamat.2015.06.049

[10] S. Lee, Z. Horita: Materials Transactions , Vol. 53, 2012, p. 38-45, https://doi.org/10.2320/matertrans.MD201109

[11] K. Edalati, S. Toh, M. Watanabe, Z. Horita: Scripta Materialia, Vol. 66, 2012, p. 386-389, https://doi.org/10.1016/j.scriptamat.2011.11.039

[12] J. M. Cubero-Sesin, Z. Horita: Materials Transactions, Vol. 53, 2012, p. 46-55, https://doi.org/10.2320/matertrans.MD201110

[13] K. Bryła, J. Morgiel, M. Faryna, K. Edalati, Z. Horita: Materials Letters, Vol. 212, 2018, p. 323-326, https://doi.org/10.1016/j.matlet.2017.10.113

[14] A. A. Mazilkin, B. B. Straumal, S. G. Protasova, O. A. Kogtenkova, R. Z. Valiev: Physics of Solid State, Vol. 49, 2007, p. 868-873, https://doi.org/10.1134/S1063783407050113 
[15] B. B. Straumal et al.: Journal of Materials Sciencs, Vol. 46, 2011, p. 4243-4247, https://doi.org/10.1007/s10853-011-5257-6

[16] K. Edalati et al.: Materials Transactions, Vol. 57, 2016, p. 533-538, https://doi.org/ 10.2320/matertrans.M2015374

[17] K. Edalati, Y. Hashiguchi, P.H.R. Pereira, Z. Horita, T. G. Langdon: Materials Science and Engineering A, Vol. 714, 2018, p. 167-171, https://doi.org/10.1016/j.msea.2017.12.095

[18] K. Edalati, Z. Horita: Acta Materialia, Vol. 59, 2011, p. 6831-6836, https://doi.org/ 10.1016/j.actamat.2011.07.046

[19] K. Edalati, Z. Horita, T. Furuta, S. Kuramoto: Materials Science and Engineering A, Vol. 559, 2013, p. 506-509, https://doi.org/10.1016/j.msea.2012.08.132

[20] A.A. Mazilkin, O.A. Kogtenkova, B.B. Straumal, R.Z. Valiev, B. Baretzky: Defect and Diffusion Forum, Vol. 237-240, 2005, p. 739-744, https://doi.org/10.4028/www.scientific.net/DDF.237.739

[21] A. A. Mazilkin et al.: Defect and Diffusion Forum, Vol. 249, 2006, p. 155-160, https://doi.org/10.4028/www.scientific.net/DDF.249.155

[22] R. Kulagin, Y. Beygelzimer, Yu. Ivanisenko, A. Mazilkin, B. Straumal, H. Hahn: Materials Letters, Vol. 222, 2018, p. 172-175, https://doi.org/10.1016/j.matlet.2018.03.200

[23] R. Z. Valiev, R. K. Islamgaliev, I. V. Alexandrov: Progress in Materials Science, Vol. 45, 2000, p. 103-189, https://doi.org/10.1016/S0079-6425(99)00007-9

[24] K. Bryła et al.: Materials Science and Engineering A, Vol. 737, 2018, p. 318-327, https://doi.org/10.1016/j.msea.2018.09.070

[25] E. A. Lukyanova et al.: Russian Metallurgy (Metally), Vol. 11, 2017, p. 912-921, https://doi.org/10.1134/S0036029517110088

[26] P. Kral et al.: Materials Science and Engineering A, Vol. 723, 2018, p. 287-295, https://doi.org/10.1016/j.msea.2018.03.059

[27] S. Sabbaghianrad, S.A. Torbati-Sarraf, T.G. Langdon: Materials Science and Engineering A, Vol. 712, 2018, p. 373-379, https://doi.org/ 0.1016/j.msea.2017.11.090

[28] K. Tirsatine et al.: Journal of Alloys and Compounds, Vol. 753, 2018, p. 46-53, https://doi.org/10.1016/j.jallcom.2018.04.194

[29] M. Y. Alawadhi, S. Sabbaghianrad, Y. Huanga, T.G. Langdon: Journal of Materials Research and Technology, Vol. 6, 2017, p. 369-377, https://doi.org/10.1016/j.jmrt.2017.05.005

[30] M. Azabou et al.: The International Journal of Advanced Manufacturing Technology, Vol. 87, 2016, p. 981-987, https://doi.org/10.1007/s00170-016-8551-2

[31] A. A. Mazilkin et al.: Acta Materialia, Vol. 54, 2006, p. 3933-3939, https://doi.org/10.1016/j.actamat.2006.04.025

[32] B. Straumal et al.: Materials Letters, Vol. 118, 2014, p. 111-114, https://doi.org/10.1016/j.matlet.2013.12.042

[33] Y. Huang, S. Sabbaghianrad, A.I. Almazrouee, K.J. Al-Fadhalah, S.N. Alhajeri, T.G. Langdon: Materials Science and Engineering A, Vol. 656, 2016, p. 55-66, https://doi.org/10.1016/j.msea.2016.01.027

[34] N. Lugo, N. Llorca, J.M. Cabrera, Z. Horita: Materials Science and Engineering A, Vol. 477, 2008, p. 366-371, https://doi.org/10.1016/j.msea.2016.01.027

[35] J. Č́žek et al.: Acta Materialia, Vol. 59, 2011, p. 2322-2329, https://doi.org/10.1016/j.actamat.2010.12.028

[36] X. Z. Liao, Y. H. Zhao, Y. T. Zhu, R. Z. Valiev, D. V. Gunderov: Journal of Applied Physics, Vol. 96, 2004, p. 636-640, https://doi.org/10.1063/1.1757035 
[37] M. Shamsborhan, M. Ebrahimi: Journal of Alloys and Compounds, Vol. 682, 2016, p. 552556, https://doi.org/ 10.1016/j.jallcom.2016.05.012

[38] C. L. Tang, H. Li, S. Y. Li: The Transactions of Nonferrous Metals Society of China, Vol. 26, 2016, p. 1736-1744, https://doi.org/10.1016/S1003-6326(16)64286-3

[39] Z. N. Mao et al.: Materials Science and Engineering A, Vol. 674, 2016, p. 186-192, https://doi.org/10.1016/j.msea.2016.07.050

[40] E. Bagherpour, F. Qods, R. Ebrahimi, H. Miyamoto: Materials Science and Engineering A, Vol. 674, 2016, p. 221-231, https://doi.org/10.1016/j.msea.2016.08.001

[41] E. Bagherpour, F. Qods, R. Ebrahimi, H. Miyamoto: Materials Science and Engineering A, Vol. 666, 2016, p. 324-338, https://doi.org/10.1016/j.msea.2016.04.080

[42] P.C. Yadav, A. Sinhal, S. Sahu, A. Roy, S. Shekhar: Journal of Materials Engineering and Performance, Vol. 25, 2016, p. 2604-2614, https://doi.org/10.1007/s11665-016-2142-0

[43] C. Xu, Z. Horita, T.G. Langdon: Materials Science and Engineering A, Vol. 528, 2011, p. 6059-6065, https://doi.org/10.1016/j.msea.2011.04.017

[44] K. Edalati, Z. Horita: Materials Science and Engineering A, Vol. 528, 2011, p. 7514- 7523, https://doi.org/10.1016/j.msea.2011.06.080

[45] A. V. Korznikov, Y. V. Ivanisenko, D. V. Laptionok, I. M. Safarov, V. P. Pilyugin, R. Z. Valiev: Nanostructured Materials, Vol. 4, 1994, p. 159-167, https://doi.org/10.1007/s11665016-2142-0

[46] Y. Ivanisenko, W. Lojkowski, R. Z. Valiev, H.-J. Fecht: Acta Materialia, Vol. 51, 2003, p. 5555-5570, https://doi.org/ 10.1016/S1359-6454(03)00419-1

[47] Y. Ivanisenko, R.K. Wunderlich, R.Z. Valiev, H.-J. Fecht: Scripta Materialia, Vol. 49, 2003, p. 947-952, https://doi.org/10.1016/S1359-6462(03)00478-0

[48] J. Zrnik, R. Pippan, S. Scheriau, L. Kraus, M. Fujda: Journal of Materials Science 45, 2010, p. 4822-4826, https://doi.org/10.1007/s10853-010-4482-8

[49] S. Bayramoglu, C. H. Gür, I. V. Alexandrov, M. M. Abramova: Materials Science and Engineering A, Vol. 527, 2010, p. 927-933, https://doi.org/10.1016/j.msea.2009.09.006

[50] J. Ningn et al.: Materials Science and Engineering A, Vol. 581, 2013, p. 8-15, https://doi.org/10.1016/j.msea.2013.05.008

[51] Y. Todaka, Y. Miki, M. Umemoto, C. Wang, K. Tsuchiya: Materials Science Forum, Vol. 584-586, 2008, p. 597-604, https://doi.org/10.4028/www.scientific.net/DSF.584.597

[52] X. Z. Liao et al.: Applied Physics Letters, Vol. 88, 2006, p. 021909, https://doi.org/10.1063/1.2159088

[53] R. Pippan, S. Scheriau, A. Taylor, M. Hafok, A. Hohenwarter, A. Bachmaier: Annual Review of Materials Research, Vol. 40, 2010, p. 319-343, https://doi.org/ 10.1146/annurevmatsci-070909-104445

[54] H. Wen, R.K. Islamgaliev, K.M. Nesterov, R.Z. Valiev, E.J. Lavernia: Philosophical Magazine Letters, Vol. 93, 2013, p. 481-489, https://doi.org/10.1080/09500839.2013.805268

[55] K. Edalati et al.: Acta Materialia, Vol. 69, 2014, p. 68-77, https://doi.org/10.1016/j.actamat.2014.01.036

[56] R. Tejedora, K. Edalati, J.A. Benito, Z. Horita, J. M. Cabrera: Materials Science and EngineeringA, Vol. 743, 2019, p. 597-605, https://doi.org/10.1016/j.msea.2018.11.127

[57] I. F. Mohamed et al.: Materials Science and Engineering A, Vol. 704, 2017, p. 112-118, https://doi.org/10.1016/j.msea.2017.07.083 
[58] K. Edalati, H. Shao, H. Emami, H. Iwaoka, E. Akiba, Z. Horita: International Journal of Hydrogen Energy, Vol. 41, 2016, p. 8917-8924, https://doi.org/10.1016/j.ijhydene.2016.03.146

[59] M. Isika et al.: Journal of the Mechanical Behavior of Biomedical Materials, Vol. 59, 2016, p. 226-235, https://doi.org/10.1016/j.jmbbm.2015.11.015

[60] M. Isik et al.: Materials Transactions, Vol. 57, 2016, p. 1109-1118, https://doi.org/10.2320/matertrans.M2016052

[61] T. Hongo et al.: Materials Science and Engineering A, Vol. 618, 2014, p. 1-8, https://doi.org/10.1016/j.msea.2014.08.074

[62] K. Edalati, K. Imamura, T. Kiss, Z. Horita: Materials Transactions, Vol. 53, 2012, p. 123127, https://doi.org/10.2320/matertrans.MD201109

[63] A. Hanna et al.: Journal of Alloys and Compounds, Vol. 778, 2019, p. 61-71, https://doi.org/10.1016/j.jallcom.2018.11.109

[64] Y. I. Bourezg et al.: Materials Science and Engineering A, Vol. 724, 2018, p. 477-485, https://doi.org/10.1016/j.msea.2018.03.114

[65] P. Bazarnik, Y. Huang, M. Lewandowska, T. G. Langdon: Materials Science and Engineering A, Vol. 712, 2018, p. 513-520, https://doi.org/10.1016/j.msea.2017.12.007

[66] D. M. M. Cardona, J. Wongsa-Ngam, H. Jimenez, T. G. Langdon: Journal of Materials Research and Technology, Vol. 6, 2017, p. 355-360, https://doi.org/10.1016/j.jmrt.2017.05.002

[67] S. A. Torbati-Sarraf, S. Sabbaghianrad, R. B. Figueiredo, T. G. Langdon: Journal of Alloys and Compounds, Vol. 712, 2017, p. 185-193, https://doi.org/10.1016/j.jallcom.2017.04.054

[68] M. Diez, H.-E. Kim, V. Serebryany, S. Dobatkin, Y. Estrin: Materials Science and Engineering A, Vol. 612, 2014, p. 287-292, https://doi.org/10.1016/j.msea.2014.06.061

[69] E. A. Lukyanova, N. S. Martynenko, I. Shakhova, A. N. Belyakov, L. L. Rokhlin, S. V. Dobatkin, Y. Z. Estrin: Materials Letters, Vol. 170, 2016, p. 5-9, https://doi.org/10.1016/j.matlet.2016.01.106

[70] N. S. Martynenko, E. A. Luk’yanova, M. M. Morozov, V. S. Yusupov, S. V. Dobatkin, Y. Z. Estrin: Metal Science and Heat Treatment, Vol. 60, 2018, p. 253-258, https://doi.org/10.1007/s11041-018-0269-3

[71] C. C. Koch, T. G. Langdon, E. J. Lavernia: Metallurgical and Materials Transactions A, Vol. 48, 2017, p. 5181-5199, https://doi.org/s11661-017-4298-0

[72] A. A. Mazilkin, B. B. Straumal, M. V. Borodachenkova, R. Z. Valiev, O. A. Kogtenkova, B. Baretzky: Materials Letters, Vol. 84, 2012, p. 63-65, https://doi.org/10.1016/j.matlet.2012.06.026

[73] B. B. Straumal et al.: Acta Materialia, Vol. 52, 2004, p. 4469-4478, https://doi.org/10.1016/j.actamat.2004.06.006

[74] Y. Ito, K. Edalati, Z. Horita: Materials Science and Engineering A, Vol. 679, 2017, p. 428434, https://doi.org/ 0.1016/j.msea.2016.10.066

[75] X. Sauvage, M. Yu. Murashkin, B. B. Straumal, E. Bobruk, R. Z. Valiev: Advanced Engineering Materials , Vol. 17, 2015, p. 1821-1827, https://doi.org/10.1002/adem.201500151

[76] V. D. Sitdikov, P. S. Chizhov, M. Yu. Murashkin, R. Z. Valiev: Reviews on Advanced Materials Science, Vol. 47, 2016, p. 59-65

[77] A. Korneva et al.: Inżynieria Materiałowa, Vol. 34, 2013, p. 306-309, https://doi.org/10.15199/34.2013.4.6 
[78] B. B. Straumal et al.: Materials Letters, Vol. 98, 2013, p. 217-221, https://doi.org/10.1016/j.matlet.2013.02.058

[79] L. von Bertalanffy, Science, Vol. 111, 1950, p. 23-29, https://doi.org/10.1126/science.111.2872.23

[80] B. B. Straumal et al.: Journal of Materials Science, Vol. 47, 2012, p. 360-367, https://doi.org/10.1007/s10853-011-5805-0

[81] B. B. Straumal et al.: JETP Letters, Vol. 100, 2014, p. 376-379, https://doi.org/10.1134/S0021364014180106

[82] A. Korneva et al.: Materials Letters, Vol. 179, 2016, p. 12-15, https://doi.org/10.1016/j.matlet.2016.05.059

[83] A. Korneva, B. Straumal, A. Kilmametov, G. Cios, P. Bała, P. Zięba: Materials Characterisation, Vol. 118, 2016, p. 411-416, https://doi.org/10.1016/j.matchar.2016.06.019

[84] A. Korneva et al.: IOP Conference Series: Materials Science and Engineering, Vol. 63, 2014, p. 012093, https://doi.org/10.1088/1757-899X/63/1/012093

[85] B.B. Straumal et al.: Materials Letters, Vol. 138, 2015, p. 255-258, https://doi.org/10.1016/j.matlet.2014.10.009

[86] A. Korneva, B. Straumal, A. Kilmametov, R. Chulist, P. Straumal, P. Zięba: Materials Characterisation, Vol. 114, 2016, p. 151-156, https://doi.org/10.1016/j.matchar.2016.02.017

[87] B. B. Straumal, V. Pontikis, A. R. Kilmametov, A. A. Mazilkin, S. V. Dobatkin, B. Baretzky: Acta Materialia, Vol. 122, 2017, p. 60-71, https://doi.org/10.1016/j.actamat.2016.09.024

[88] A. Korneva et al.: Materials , Vol. 12, 2019, p. 447, https://doi.org/10.3390/ma12030447

[89] B. B. Straumal et al.: International Journal of Materials Research , Vol. 110, 2019, p. 608613, https://doi.org/10.3139/146.111784

[90]G. A. López et al.: Materials Today: Proceedings, Vol. 2S, 2015, p. S747-S750, https://doi.org/10.1016/j.matpr.2015.07.390

[91] B. B. Straumal et al.: Acta Materialia, Vol. 125, 2017, p. 274-285, https://doi.org/10.1016/j.actamat.2016.12.003

[92] G. Martin: Physical Review B, Vol. 30, 1984, p. 1424-1436, https://doi.org/10.1103/PhysRevB.30.1424

[93] B. B. Straumal et al.: Kovove Materialy-Metallic Materials, Vol. 49, 2011, p. 17-22, https://doi.org/10.4149/km-2011-1-17

[94] A. A. Mazilkin et al.: Journal of Materials Science, Vol. 46, 2011, p. 4336-4342, https://doi.org/10.1007/s10853-011-5304-3

[95] U. R. Kattner: Journal of Materials (JOM), Vol. 49, 1997, p. 14-19, https://doi.org/10.1007/s11837-997-0024-5

[96] N. Mattern, U. Kühn, A. Gebert, A. Schoeps, T. Gemminga, L. Schultz: Materials Science and Engineering A, Vol. 449/451, 2007, p. 207-210, https://doi.org/ 0.1016/j.msea.2006.02.269

[97] S. D. Prokoshkin et al.: Acta Materialia, Vol. 53, 2005, p. 2703-2714, https://doi.org/ 0.1016/j.actamat.2005.02.032

[98] A. V. Sergueeva, C. Song, R. Z. Valiev, A. K. Mukherjee: Materials Science and Engineering A, Vol. 339, 2003, p. 159-165, https://doi.org/10.1016/S0921-5093(02)00122-3

[99] X. Sauvage, L. Renaud, B. Deconihout, D. Blavette, D. H. Ping, K. Hono: Acta Materalia, Vol. 49, 2001, p. 389-394, https://doi.org/10.1016/S1359-6454(00)00338-4

[100] T. Miyazaki et al.: Journal of Materials Science, Vol. 46, 2011, p. 4296-4301, https://doi.org/10.1007/s10853-010-5240-7 
[101] V.V. Stolyarov, D.V. Gunderov, A.G. Popov, V.S. Gaviko, A. S. Ermolenko: Journal of Alloys and Compounds, Vol. 281, 1998, p. 69-71, https://doi.org/10.1016/S09258388(98)00774-9

[102] Y. Matsuura, S. Hirosawa, H. Yamamoto, S. Fujimira, M. Sagawa, K. Osamura: Japanese Journal of Applied Physics Part 2 - Letters, Vol. 24, 1985, p. L635- L637, https://doi.org/10.1143/JJAP.24.L635

[103] Á. Révész, S. Hóbor, J. L. Lábár, A. P. Zhilyaev, Zs. Kovácz: Journal of Applied Physics, Vol. 100, 2006, p. 103522, https://doi.org/10.1063/1.2388868

[104] A. M. Glezer, M. R. Plotnikova, A. V. Shalimova, S. V. Dobatkin: Bulletin of the Russian Academy of Sciences. Physics, Vol. 73, 2009, p. 1233-1236, https://doi.org/10.3103/S1062873809090123

[105] S. Hóbor, Á. Révész, A. P. Zhilyaev, Zs. Kovácz: Reviews of Advanced Materials Science, Vol. 18, 2008, p. 590-592

[106] Zs. Kovács, P. Henits, A. P. Zhilyaev, Á. Révész: Scripta Materialia, Vol. 54, 2006, p. 1733-1737, https://doi.org/10.1016/j.scriptamat.2006.02.004

[107] G. E. Abrosimova et al.: Journal of Metastable and Nanocrystalline Materials, Vol. 24, 2005, p. 69-72, https://doi.org/10.4028/www.scientific.net/JMNM.24-25.69

[108] Á. Révész, E. Schafler, Zs. Kovács: Applied Physics Letters, Vol. 92, 2008, p. 011910, https://doi.org/10.1063/1.3064125

[109] S. Hóbor, Zs. Kovács, A. P. Zhilyaev, L. K. Varga, P. J. Szabó, Á. Révész: Journal of Physics, Vol. 240, 2010, p. 012153, https://doi.org/10.1088/1742-6596/240/1/012153

[110] S. Hóbor et al.: Journal of Applied Physics, Vol. 104, 2008, p. 033525, https://doi.org/10.1063/1.2964115

[111] P. Henits, Á. Révész, A. P. Zhilyaev, Zs. Kovács: Journal of Alloys and Compounds, Vol. 461, 2008, p. 195-199, https://doi.org/10.1016/j.jallcom.2007.07.049

[112] Zs. Kovács, P. Henits, A.P. Zhilyaev, N.Q. Chinh, Á. Révész: Materials Science Forum, Vol. 519-521, 2006, p. 1329-1334, https://doi.org/10.4028/www.scientific.net/DDF.519.1329

[113] B. Oberdorfer et al.: Physical Review Letters, Vol. 105, 2010, p. 146101, https://doi.org/10.1103/PhysRevLett.105.146101

[114] J. Čížek, O. Melikhova, Z. Barnovská, I. Procházka, R. K. Islamgaliev: Journal of Physics: Conference Series, Vol. 443, 2013, p. 012008, https://doi.org/10.1088/1742$6596 / 443 / 1 / 012008$

[115] B. B. Straumal, O. A. Kogtenkova, R. Z. Valiev, P. Zięba, B. Baretzky: Diffusion Fundamentals, Vol. $\quad 5, \quad$ 2015, p. https://doi.org/10.4028/www.scientific.net/DF.5.95

[116] T. Ungar, E. Schafler, P. Hanak, S. Bernstorff, M. Zehetbauer: Materials Science and Engineering A, Vol. 462, 2007, p. 398-401, https://doi.org/10.1016/j.msea.2006.03.156

[117] T. Ungár, E. Schafler, P. Hanák, S. Bernstorff, M. Zehetbauer: Zeitschrift für Metallkunde, Vol. 96, 2005, p. 578-583, https://doi.org/10.3139/146.101073

[118] C. A. Mackliet: Physical Review, Vol. 109, 1958, p. 1964-1970, https://doi.org/10.1103/PhysRev.109.1964

[119] S. Fujikawa, K.I. Hirano, in: Proc. of Yamada Vth Conf. on Point Defects, Defect Interactions in Metals, J.I. Takamura, M. Doyama, M. Kiritani (Eds.) University of Tokyo Press, 1982, p. 554-558. 
[120] D. A. Molodov, B. B. Straumal, L. S. Shvindlerman: Scripta Metallurgica, Vol. 18, 1984, p. 207-211, https://doi.org/10.1016/0036-9748(84)90509-X

[121] B. B. Straumal, L. M. Klinger, L. S. Shvindlerman: Scripta Metallurgica, Vol. 17, 1983, p. 275-279, https://doi.org/10.1016/0036-9748(83)90156-4

[122] B. B. Straumal et al.: Philosophical Magazine Letters, Vol. 89, 2009, p. 649-654, https://doi.org/10.1080/09500830903246268

[123] B. B. Straumal et al.: Materials Letters, Vol. 81, 2012, p. 225-228, https://doi.org/10.1016/j/matlet.2012.04.153

[124] B. B. Straumal, A. S. Gornakova, O. B. Fabrichnaya, M. J. Kriegel, A. A. Mazilkin, B. Baretzky, A. M. Gusak, S. V. Dobatkin: High Temp. Mater. Proc. , Vol. 31, 2012, p. 339350, https://doi.org/10.1515/htmp-2012-0057

[125] A. Kilmametov et al.: Scripta Materialia, Vol. 136, 2017, p. 46-49, https://doi.org/10.1016/j.scriptamat.2017.04.010

[126] A. Kilmametov et al.: Acta Materialia, Vol. 144, 2018, p. 337-351, https://doi.org/10.1016/j.actamat.2017.10.051

[127] B. B. Straumal et al.: Journal of Alloys and Compounds, Vol. 735, 2018, p. 2281-2286, https://doi.org/10.1016/j.jallcom.2017.11.317

[128] A. R. Kilmametov, Yu. Ivanisenko, B. B. Straumal, A. S. Gornakova, A. A. Mazilkin, H. Hahn: Metals, Vol. 8, 2018, p. 1-12, https://doi.org/10.3390/met8010001

[129] A. S. Gornakova et al.: Journal of Applied Physics, Vol. 125, 2019, p. 082522, https://doi.org/10.1063/1.5053937

[130] B. B. Straumal et al.: Materials, Vol. 12, 2019, p. 426, https://doi.org/10.3390/ma12030426

[131] B. B. Straumal et al.: Advanced Engineering Materials, Vol. 17, 2015, p. 1835-1841, https://doi.org/10.1002/adem.201500143

[132] M. J. Kriegel et al.: Advanced Engineering Materials, Vol. 20, 2018, p. 1700933, https://doi.org/10.1002/adem.201700933

[133] B. Chon et al.: Scripta Materialia, Vol. 157, 2018, p. 120-123, https://doi.org/10.1016/j.scriptamat.2018.08.011

[134] Y. Ikoma, K. Kumano, K. Edalati, M. R. McCartney, D. J. Smith, Z. Horita: Materials $\begin{array}{lllll}\text { Characterization, } \quad \text { Vol. } & \text { 132, 2017, } & \text { 132-138, }\end{array}$ https://doi.org/10.1016/j.matchar.2017.08.011

[135] Y. Fukushima, Y. Ikoma, K. Edalati, B. Chon, D. J. Smith, Z. Horita: Materials Characterization, Vol. 129, 2017, p. https://doi.org/10.1016/j.matchar.2017.04.025

[136] Y. Qi, A. Kosinova, A. R. Kilmametov, B. B. Straumal, E. Rabkin: Materials Characterization, Vol. 145, 2018, p. https://doi.org/10.1016/j.matchar.2018.09.001

[137] K. Edalati, I. Fujita, X. Sauvage, M. Arita, Z. Horita: Journal of Alloys and Compounds, Vol. 779, 2019, p. 394-398, https://doi.org/10.1016/j.jallcom.2018.11.086

[138] K. Edalati, Q. Wang, H. Razavi-Khosroshahi, H. Emami, M. Fuji, Z. Horita: Scripta Materialia, Vol. 162, 2019, p. 341-344, https://doi.org/10.1016/j.scriptamat.2018.11.044

[139] H. Razavi-Khosroshahi, K. Edalati, M. Arita, Z. Horita, M. Fuji: Scripta Materialia, Vol. 124, 2016, p. 59-62, https://doi.org/10.1016/j.scriptamat.2016.06.022

[140] W. Zhong, D. Venderbilt, K.M. Rabe: Physical Review Letters, Vol. 73, 1994, p. 18611864, https://doi.org/10.1103/PhysRevLett.73.1861 
[141] T. Ishidate, S. Abe, H. Takahashi, N. Mori: Physical Review Letters, Vol. 78, 1997, p. 2397-2400, https://doi.org/ 10.1103/PhysRevLett.78.2397

[142] S. A. Hayward, E. K. H. Salje: Journal of Physics: Condensed Matter, Vol. 14, 2002, p. L599-L604, https://doi.org/10.1088/0953-8984/14/36/101

[143] J. J. Wang, P. P. Wu, X. Q. Ma, L. Q. Chen: Journal of Applied Physics, Vol. 108, 2010, p. 114105, https://doi.org/10.1063/1.3504194

[144] U. D. Venkateswaran, V. M. Naik, R. Naik: Physical Review B, Vol. 58, 1998, p. 1425614260, https://doi.org/10.1103/PhysRevB.58.14256

[145] K. Edalati et al.: Materials Research Letters, Vol. 3, 2015, p. 216-221, https://doi.org/10.1080/21663831.2015.1065454

[146] R. C. Garvie, R. H. J. Hannink, R. T. Pascoe: Nature, Vol. 258, 1975, p. 703-704, https://doi.org/10.1038/258703a0

[147] R. H. J. Hannink, P. M. Kelly, B. C. Muddle: Journal of American Ceramic Society, Vol. 83, 2000, p. 461-487, https://doi.org/10.1111/j.1151-2916.2000.tb01221.x

[148] J. M. Leger, P. E. Tomaszewski, A. Atouf, A. S. Pereira: Physical Review B, Vol. 47, 1993, p. 14075-14083, https://doi.org/ 10.1103/PhysRevB.47.14075

[149] K. Edalati, S. Toh, Y. Ikoma, Z. Horita: Scripta Materialia, Vol. 65, 2011, p. 974-977, https://doi.org/10.1016/j.scriptamat.2011.08.024

[150] E. I. Rabkin, L. S. Shvindlerman, B. B. Straumal: International Journal of Modern Physics B, Vol. 5, 1991, p. 2989-3028, https://doi.org/10.1142/S0217979291001176

[151] B. B. Straumal, O. I. Noskovich, V. N. Semenov, L. S. Shvindlerman, W. Gust, B. Predel: Acta Metallurgica et Materialia, Vol. 40, 1992, p. 795-801, https://doi.org/10.1016/09567151(92)90021-6

[152] B. B. Straumal, W. Gust, T. Watanabe: Materials Science Forum, Vol. 294/296, 1999, p. 411-414, https://doi.org/10.4028/www.scientific.net/DDF.294.411

[153] B. B. Straumal et al.: Reviews of Advanced Materials Science, Vol. 38, 2014, p. 17-28

[154] A. B. Straumal, K. V. Tsoi, I. A. Mazilkin, A. N. Nekrasov, K. Bryła: Archives of Metallurgy and Materials, 64, 2019, p. 869-873, https://doi.org/10.24425/amm.2019.129463

[155] L.-S. Chang, B.B. Straumal, E. Rabkin, W. Gust, F. Sommer: Journal of Phase Equilibria, Vol. 18, 1997, p. 128-135, https://doi.org/10.1007/BF02665694

[156] L. S. Chang, E. Rabkin, B. Straumal, P. Lejcek, S. Hofmann, W. Gust: Scripta Materialia, Vol. 37, 1997, p. 729-735, https://doi.org/10.1016/S1359-6462(97)00171-1

[157] L. S. Chang, E. Rabkin, B. B. Straumal, S. Hoffmann, B. Baretzky, W. Gust: Defect and Diffusion Forum, Vol. 156, 1998, p. 135-146, https://doi.org/10.4028/www.scientific.net/DDF.156.135

[158] B. B. Straumal, P. Zięba, W. Gust: International Journal of Inorganic Materials, Vol. 3, 2001, p. 1113-1115, https://doi.org/10.1016/S1466-6049(01)00108-8

[159] B. B. Straumal, A. O. Rodin, A. E. Shotanov, A. B. Straumal, O. A. Kogtenkova, B. Baretzky: Defect and Diffusion Forum, Vol. 333, 2013, p. 175-192, https://doi.org/10.4028/www.scientific.net/DDF.333.175

[160] B. B. Straumal, A. A. Mazilkin, S. G. Protasova, G. Schütz, A. B. Straumal, B. Baretzky: Journal of Materials Engineering and Performance, Vol. 25, 2016, p. 3303-3309, https://doi.org/10.1007/s11665-015-1872-8

[161] B. B. Straumal, A. A. Mazilkin, B. Baretzky: Current Opinion in Solid State \& Materials Science, Vol. 20, 2016, p. 247-256, https://doi.org/10.1016/j.cossms.2016.05.006 
[162] B. Straumal et al.: Acta Materialia, Vol. 56, 2008, p. 6123-6131, https://doi.org/10.1016/j.actamat.2008.08.021

[163] O. A. Kogtenkova et al.: Journal of Materials Science, Vol. 47, 2012, p. 8367-8371, https://doi.org/10.1007/s10853-012-6786-3

[164] O. A. Kogtenkova, B. B. Straumal, S. G Protasova, A. S. Gornakova, P. Zięba, T. Czeppe: JETP Letters, Vol. 96, 2012, p. 380-384, https://doi.org/10.1134/S0021364012180063

[165] O. A. Kogtenkova, P. Zieba, T. Czeppe, L. Lityn'ska-Dobrzynska, B.B. Straumal, A.N. Nekrasov: Bulletin of the Russian Academy of Sciences: Physics, Vol. 77, 2013, p. 13861390, https://doi.org/10.3103/S1062873813110166

[166] K. Higashi, T. G. Nieh, M. Mabuchi, J. Wadsworth: Scripta Metallurgica et Materialia, Vol. 32, 1995, p. 1079-1084, https://doi.org/10.1016/0956-716X(94)00003-Z

[167] Y. Takayama, T. Tozawa, H. Kato: Acta Materialia, Vol. 47, 1999, p. 1263-1270, https://doi.org/10.1016/S1359-6454(98)00416-9

[168] H. Iwasaki, T. Mori, M. Mabuchi, K. Higashi: Acta Materialia, Vol. 46, 1998, p. 63516360, https://doi.org/10.1016/S1359-6454(98)00330-9

[169] B. Baudelet, M. C. Dang, F. Bordeaux: Scripta Metallurgica et Materialia, Vol. 26, 1992, p. 573-578, https://doi.org/10.1016/0956-716X(92)90286-N

[170] B. B. Straumal et al.: Materials Science and Engineering A, Vol. 503, 2009, p. 185-189, https://doi.org/10.1016/j.msea.2008.03.052

[171] B. B. Straumal et al.: Defect and Diffusion Forum, Vol. 309-310, 2011, p. 51-62, https://doi.org/10.4028/www.scientific.net/DDF.309.319

[172] B. B. Straumal et al.: Advanced Engineering Materials, Vol. 13, 2011, p. 463-469, https://doi.org/10.1002/adem. 201000312

[173] Yu. Ivanisenko, X. Sauvage, A. Mazilkin, A. Kilmametov, J.A. Beach, B.B. Straumal: Advanced Engineering Materials, Vol. 20, 2018, p. 1800443, https://doi.org/10.1002/adem.201800443

[174] B. Straumal et al.: Acta Materialia, Vol. 56, 2008, p. 6123-6131, https://doi.org/10.1016/j.actamat.2008.08.021

[175] R. Z. Valiev, M. Yu. Murashkin, B. B. Straumal: Materials Science Forum, Vol. 633-634, 2009, p. 321-332, https://doi.org/10.4028/www.scientific.net/DSF.633.321

[176] R. Z. Valiev, M. Y. Murashkin, A. Kilmametov, B. B. Straumal, N. Q. Chinh, T. G. Langdon: Journal of Materials Science, Vol. 45, 2010, p. 4718-4724, https://doi.org/10.1007/s10853-010-4588-Z

[177] N. Q. Chinh, T. Csanádi, J. Gubicza, R. Z. Valiev, B. B. Straumal, T. G. Langdon: Materials Science Forum, Vol. 667-669, 2011, p. 677-682, https://doi.org/10.4028/www.scientific.net/DSF.667.677

[178] O. A. Kogtenkova et al.: Journal of Materials Science, Vol. 48, 2013, p. 4758-4765, https://doi.org/10.1007/s10853-013-7266-0

[179] B. B. Straumal, X. Sauvage, B. Baretzky, A. A. Mazilkin, R. Z. Valiev: Scripta Materialia, Vol. 70, 2014, p. 59-62, https://doi.org/10.1016/j.scriptamat.2013.09.019

[180] N. Q. Chinh et al.: Advanced Engineering Materials, Vol. 16, 2014, p. 1000-1009, https://doi.org/10.1002/adem.201300450

[181] B. B. Straumal, A. A. Mazilkin, X. Sauvage, R. Z. Valiev, A. B. Straumal, A. M. Gusak: Russian Journal of Non-Ferrous Metals, Vol. 56, 2015, p. 44-51, https://doi.org/10.3103/S1067821215010198

[182] N. Q. Chinh et al.: Materials Science and Engineering A, Vol. 543, 2012, p. 117-120, https://doi.org/10.1016/j.msea.2012.02.056 


\section{Acknowledgements}

The authors are deeply grateful to Profs. H. Hahn, P. Zięba, Drs. Yu. Ivanisenko, and A. Gornakova for valuable suggestions and discussion. The work is partially supported by the state task of ISSP and CSC RAS, the National Science Centre of Poland (grant OPUS 2014/13/B/ST8/04247), by the Russian Foundation for Basic Research (grants 18-03-00067, 1958-06002). The part of research has been performed within the Accredited Testing Laboratories with certificate No. AB 120 issued by the Polish Centre of Accreditation according to European standard PN-ISO/IEC 17025:2005 and EA-2/15. 